\title{
Glycine Transporter-I Inhibition Preceding Extinction Training Inhibits Reacquisition of Cocaine Seeking
}

\author{
Cindy Achat-Mendes*,', Bríd Á Nic Dhonnchadha², Donna M Platt', Kathleen M Kantak ${ }^{2}$ and \\ Roger D Spealman'
}

'Division of Neuroscience, New England Primate Research Center, Harvard Medical School, Southborough, MA, USA; 'Department of Psychology, Boston University, Boston, MA, USA

\begin{abstract}
Cognitive enhancers that act by increasing glycine transmission might be useful adjuncts to cocaine-cue extinction training to deter relapse. The study investigated the effects of combining treatments of the glycine transporter-I (GlyT-I) inhibitor, Org24598, with extinction training on the subsequent reacquisition of cocaine self-administration. Squirrel monkeys and rats were trained to selfadminister cocaine under a second-order schedule of intravenous drug injection in which responding was maintained by cocaine injections and a cocaine-paired visual stimulus. During three weekly extinction sessions, saline was substituted for cocaine but responding still produced the cocaine-paired stimulus. Subjects were treated with Org24598 or vehicle, either before or after each extinction session. One week later, cocaine injections were restored, and reacquisition of cocaine self-administration was evaluated over 15 sessions. Compared with vehicle, administration of Org24598 (1.0 mg/kg in monkeys; 3.0 or $7.5 \mathrm{mg} / \mathrm{kg}$ in rats) before each extinction session significantly inhibited reacquisition of cocaine self-administration in each species. In contrast, administration of Org24598 $(1.0 \mathrm{mg} / \mathrm{kg}$ in monkeys) following, rather than preceding, each extinction session did not affect reacquisition compared with vehicle. When extinction training was replaced by cocaine self-administration or abstinence control conditions, treatment with the same doses of Org24598 resulted in reacquisition that was significantly more rapid than the reacquisition observed when Org24598 was administered before extinction training sessions. The results support the potential clinical utility of GlyT-I inhibitor pretreatments combined with cocaine-cue extinction training to inhibit relapse.
\end{abstract}

Neuropsychopharmacology (2012) 37, 2837-2845; doi:I0.1038/npp.20 I2. I55; published online 5 September 2012

Keywords: cocaine self-administration; glycine transporter-I inhibitor; extinction training; relapse

\section{INTRODUCTION}

Within the mesolimbic dopamine pathway, cocaine increases dopamine release in the nucleus accumbens, prefrontal cortex, and amygdala. Repeated drug use and increased dopamine release to these brain regions can result in a sensitized reward system and enhanced reinforcing salience of drugs of abuse, as well as drug-associated stimuli (Robinson and Berridge, 2001). Compelling evidence for the biological significance of the conditioned effects of cocaine-associated stimuli comes from neuroimaging studies in which positron emission tomography and functional magnetic resonance imaging have revealed that presentation of objects or words associated with cocaine use can stimulate dopamine release, limbic system activation, and physiological responses indicative of craving in cocaine users (Childress et al, 1999; Goldstein et al, 2009; Kilts et al, 2001; Volkow et al, 2006; Wong

*Correspondence: Dr C Achat-Mendes, New England Primate Research Center, Harvard Medical School, I Pine Hill Dr, PO Box 9102, Southborough, MA, USA, Tel: +6173539201, Fax: + 617353 2894, E-mail: cindy_achat-mendes@hms.harvard.edu

Received 25 January 2012; revised 13 June 20 I2; accepted 6 July 2012 et al, 2006). As cocaine-associated stimuli by themselves can prime the memory of cocaine reinforcement and elicit craving, the concept of reducing the salience of such stimuli through extinction training has been proposed as a potential therapeutic strategy (ie, cue-exposure therapy; Cleva et al, 2010; Myers et al, 2011).

During extinction, repeated presentations of drug-associated stimuli in the absence of drug can promote new learning that competes with previously established drug-cue associations. This process of extinction learning recruits brain regions that mediate learning and memory, including the prefrontal cortex, amygdala, and hippocampus, and is facilitated by glutamatergic signaling between these regions (see Quirk and Mueller, 2008 for review). In particular, $N$-methylD-aspartate (NMDA) receptors have a well-documented role in the extinction of drug-cue associations (Feltenstein and See, 2007; Zweifel et al, 2008). Based on these observations, we hypothesized that pharmacological agents that enhance glutamate signaling via NMDA receptors might augment the impact of cocaine-cue extinction training.

Pharmacological and genetic manipulation of the glycine transporter-1 (GlyT-1) can alter extracellular glycine concentrations and subsequently influence NMDA receptor activity 
(Chen et al, 2003; Kinney et al, 2003; Dubroqua et al, 2010). It has been proposed that compounds that elevate extracellular glycine via inhibition of GlyT-1 activity can ameliorate cognitive deficits (Liem-Moolenaar et al, 2010; Wallace et al, 2011; Nikiforuk et al, 2011; Singer et al, 2009). Therefore, the aim of our study was to determine whether a GlyT-1 inhibitor might also enhance the consequences of extinction training in subjects with cocaine self-administration histories.

The selective GlyT-1 inhibitor Org24598 increases glycine levels in vitro (Brown et al, 2001; Mallorga et al, 2003) and in vivo in the nucleus accumbens (Lidö et al, 2011) and hippocampus (Le Pen et al, 2003) of rats. Org24598 was administered in conjunction with extinction training using a protocol based on procedures developed for cue-exposure therapy in clinical situations (see Hofmann, 2007 for review). To evaluate the effects of this combined approach on reacquisition of cocaine seeking, an intravenous cocaine selfadministration model in monkeys and rats was employed. Org24598 was administered either before or following each cocaine-cue extinction session to evaluate the contributions of acquisition and consolidation of extinction learning to the inhibition of relapse to cocaine self-administration. Additional control procedures investigated the effects of Org24598 in the absence of extinction training and extinction training in the absence of Org24598.

\section{MATERIALS AND METHODS}

\section{Animals}

Eleven adult male squirrel monkeys (Saimiri sciureus), weighing $0.8-1.2 \mathrm{~kg}$, had unlimited access to water and received a nutritionally balanced diet in their home cages to maintain stable ad libitum body weights. Thirty-four adult male Wistar rats (Crl (WI) BR; 275-300 g) had unlimited access to water in their home cages. Rats were maintained at $\geqslant 90 \%$ of a growth-adjusted ad libitum body weight throughout the study by providing $16-20 \mathrm{~g}$ of food daily. All animals were maintained in accordance with the Guide for Care and Use of Laboratory Animals (eigth edition). Research protocols for monkeys were approved by the Harvard Medical School Institutional Animal Care and Use Committee and rat protocols were approved by the Boston University Institutional Animal Care and Use Committee. Seven squirrel monkeys and all the rats were surgically implanted with venous catheters using aseptic surgical and catheter maintenance procedures, as previously described for monkeys (Platt et al, 2011) and rats (Nic Dhonnchadha et al, 2011).

\section{Apparatus}

Studies involving intravenous self-administration were conducted in ventilated, sound-attenuated chambers (Med Associates, St Albans, VT). Within the chambers, monkeys were seated in chairs facing a panel equipped with a response lever and colored stimulus lights. Rat chambers were equipped with a panel containing two response levers with a stimulus light above each lever. Catheters were connected to motordriven syringe pumps that delivered cocaine or saline at $0.18 \mathrm{ml} / \mathrm{s}$ (monkeys) or $0.03 \mathrm{ml} / \mathrm{s}$ (rats). PC-compatible computers were connected to interfaces to control the experimental events and record data.

\section{Drugs}

Cocaine hydrochloride (NIDA, Bethesda, MD or SigmaAldrich, St. Louis, MO) was dissolved in a sterile $0.9 \%$ saline solution. Org24598 (donated by Schering-Plough Research Institute, Scotland, UK or purchased from Sigma-Aldrich) was dissolved in $45 \%(\mathrm{w} / \mathrm{v})$ 2-hydroxypropyl- $\beta$-cyclodextrin and administered I'm. in a maximum volume of $0.3 \mathrm{ml} / \mathrm{kg}$ body weight (monkeys) and intraperitoneal in a volume of $1 \mathrm{ml} / \mathrm{kg}$ body weight (rats).

\section{Cocaine Self-administration Baseline}

Seven monkeys were trained to self-administer cocaine $(0.18 \mathrm{mg} / \mathrm{kg} /$ injection) by pressing a lever under a secondorder fixed-interval 5-min fixed ratio 10, FI 5 (FR10:S), schedule of intravenous drug injection similar to the schedule described by Achat-Mendes et al (2010). Rats were similarly trained to press a lever to self-administer cocaine $(0.3 \mathrm{mg} /$ $\mathrm{kg} /$ injection) under an FI 5 (FR5:S) schedule. Under the second-order schedule, completion of every FR during a 5-min FI resulted in the presentation of a 2-s light flash (cocaine-paired stimulus), and completion of the first FR after expiration of the FI resulted in simultaneous delivery of an intravenous cocaine injection and the 2-s cocainepaired stimulus. Daily sessions were 60-min long. The second-order schedule and doses of cocaine used in this study previously have been shown to maintain persistent cocaine-seeking behavior and to provide a sensitive baseline for evaluating the changes in conditioned responding maintained by cocaine-paired cues in squirrel monkeys and rats (Nic Dhonnchadha et al, 2010, 2011). Testing began after cocaine self-administration stabilized such that no systematic trends were observed in response rate or number of injections/session for $\geqslant 5$ consecutive sessions. The baseline response rate for each subject was determined by averaging the response rate across the last five cocaine self-administration sessions.

\section{Pre-session Administration of Org24598}

Following the baseline stabilization, extinction sessions were conducted once per week for three consecutive weeks. During the 6 days between weekly extinction sessions, subjects remained in their home cages. The first extinction session began $24 \mathrm{~h}$ after the last baseline self-administration session. Lever pressing was extinguished by substituting saline for cocaine while maintaining the response-contingent presentations of the cocaine-paired stimulus. Before each extinction session, Org24598 $(1.0 \mathrm{mg} / \mathrm{kg}$ in monkeys; 3.0 or $7.5 \mathrm{mg} / \mathrm{kg}$ in rats) or vehicle was administered as a pretreatment $20 \mathrm{~min}$ (monkeys) or $30 \mathrm{~min}$ (rats) before the start of the session. The doses of Org24598 used in these studies were chosen based on initial behavioral observations in monkeys (see Supplementary Table S1) and on previous findings in rats (Le Pen et al, 2003; Lidö et al, 2011). 


\section{Cocaine Self-administration Control}

To determine the effect of Org24598 under conditions in which lever pressing was not extinguished, this control experiment evaluated the effect of Org24598 on active cocaine self-administration. Org24598 $(1.0 \mathrm{mg} / \mathrm{kg}$ in monkeys, 3.0 and $7.5 \mathrm{mg} / \mathrm{kg}$ or vehicle in rats) pretreatments were administered 20 or 30 min before the self-administration control sessions, which were conducted once per week for three consecutive weeks, and were identical in all respects to the sessions conducted during baseline cocaine self-administration. As described for the extinction procedure, subjects remained in their home cages during the 6 days between weekly control sessions, and the first weekly session began $24 \mathrm{~h}$ after the last baseline session.

\section{Abstinence Control}

To further investigate the effect of Org24598 in the absence of explicit extinction training, this control experiment evaluated the effect of Org24598 during an abstinence period in which subjects were not exposed to either cocaine or cocaine-paired cues. Abstinence studies in monkeys were conducted in the subjects' home cages. Abstinence studies in rats were conducted in experimental chambers in which levers were removed and no visual stimuli or injections were delivered. Org24598 $(1.0 \mathrm{mg} / \mathrm{kg}$ in monkeys and $7.5 \mathrm{mg} / \mathrm{kg}$ or vehicle in rats) pretreatments were administered once per week for three consecutive weeks, beginning $24 \mathrm{~h}$ after the last cocaine self-administration baseline session.

\section{Post-session Administration of Org24598}

Post-session drug treatments have been used to investigate memory consolidation processes (cf. Inda et al, 2005). To investigate the potential role of consolidation of extinction learning as a mechanism by which Org24598 might influence the extinction and subsequent reacquisition of cocaine self-administration, Org24598 $(1 \mathrm{mg} / \mathrm{kg})$ or vehicle was administered to monkeys following, rather than preceding, each of the three weekly extinction-training sessions. After each post-session injection of Org24598, subjects remained seated for $20 \mathrm{~min}$ in the experimental chamber with the door open before being returned to the home cages.

\section{Reacquisition of Cocaine Self-Administration}

Reacquisition of cocaine self-administration was evaluated beginning one week after the third weekly extinction (or self-administration or abstinence control) session. During reacquisition test sessions, all conditions and schedule parameters were identical to those established during the baseline cocaine self-administration phase, as described above. The reacquisition test lasted for 15 consecutive sessions.

\section{Re-establishing Baseline Performance}

Because of the multiple-cycle design of our study, it was necessary to re-establish stable baseline performance following the reacquisition phase of each experiment described above. Baseline cocaine self-administration typically lasted 3-5 weeks, depending on the subject until no systematic trends in response rate or number of injections/session was observed for $\geqslant 5$ consecutive sessions. The next testing cycle began once these criteria were met.

Extinction and control experiments were conducted in a quasi-randomized order in cohorts of five or six monkeys, depending on the particular experiment. The exception was the post-session Org 24598 and vehicle treatments, which were the final two conditions of the study. These two conditions were run in counterbalanced order in four monkeys, and two additional monkeys were tested with post-session Org 24598. Different cohorts of rats were used to evaluate the extinction $(n=16)$ and control $(n=18)$ test conditions. The first cohort underwent one or two cycles of baseline self-administration, followed by extinction and reacquisition test sessions. The second cohort underwent one or two cycles of baseline self-administration, followed by control (self-administration or abstinence) and reacquisition test sessions.

\section{Data Analyses}

For all phases of the study, the average response rates were determined for each session. For each subject, these response rates were transformed to a percentage of the baseline response rate generated by that subject. The baseline response rate for each subject was calculated by averaging the rate of responding during the last five cocaine self-administration sessions that preceded the particular experimental condition. This was necessary because during the baseline cocaine self-administration sessions, there was $\sim 8$-fold range in baseline response rates among individual monkeys and $\sim 5$-fold range in baseline response rates among individual rats.

For analysis of within-session patterns, the number of responses made during sequential 5-min bins of the 60-min session was determined. In addition, response rates in the first component of each extinction- and reacquisition session were measured to determine the degree to which the behavior was maintained by presentations of the conditioned stimulus before delivery of the first injection. Statistical significance was determined using repeated-measures ANOVAs (monkeys) and mixed-model ANOVAs (rats), followed by Dunnett's $t$-tests for multiple comparisons. Criterion for significance was $p<0.05$ for all analyses.

\section{RESULTS}

\section{Effects of Pre-session Org24598 on Extinction and Reacquisition of Cocaine Self-administration in Monkeys}

Compared with the high rate of responding maintained by self-administered cocaine under baseline conditions (Supplementary Table S2), the rate of responding declined markedly during extinction training under both the vehicle + extinction and Org24598 + extinction conditions (Figure 1). Under both conditions, analysis of withinsession responding across sequential 5-min bins of each session revealed a temporal pattern of responding characteristic of extinction, ie, comparatively high response during the early portion of the session and lower response rates as the session progressed (Figure 1a). This pattern of responding was confirmed statistically (main effect of 


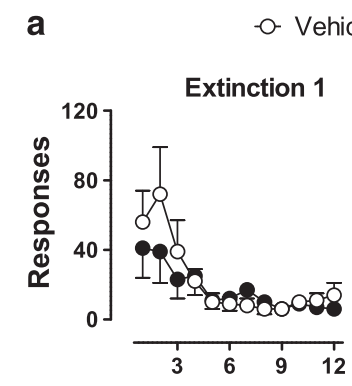

o- Vehicle - Org24598 (1 mg/kg)
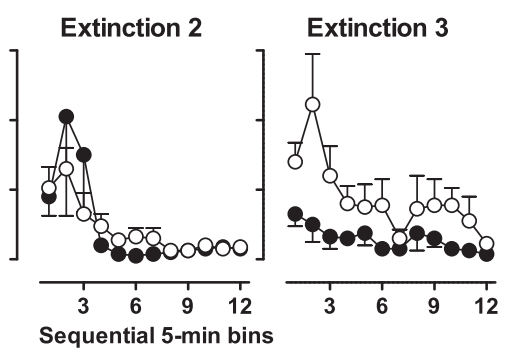

b

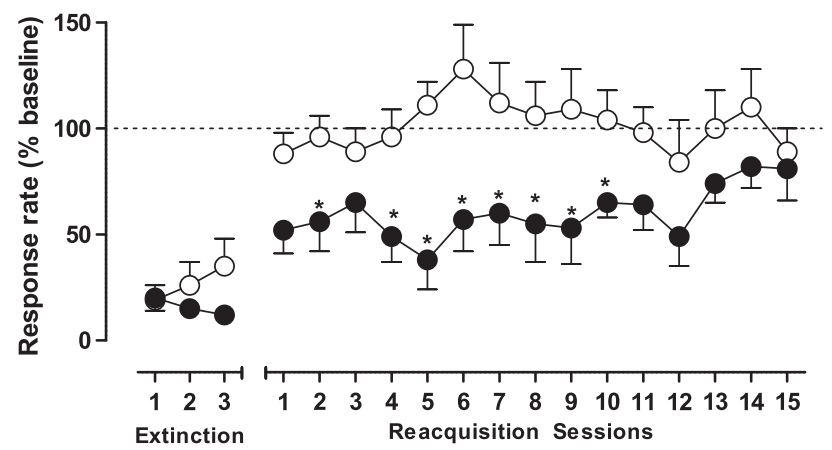

Figure I Effects of pre-session administration of Org24598 or vehicle in monkeys ( $n=6$ per group). (a) Mean ( \pm SEM) number of responses during sequential 5-min bins of each of the three weekly extinction sessions. (b) Responding during weekly extinction training sessions and daily reacquisition sessions following Org24598 + extinction and vehicle + extinction. Data are presented as mean $( \pm$ SEM) response rates expressed as a percentage of baseline responding.

sequential bins for Extinction $1(\mathrm{~F}(11,44)=5.5, p<0.001)$, Extinction $2(\mathrm{~F}(11,44)=3.7, p<0.01)$, and Extinction 3 $(\mathrm{F}(11,44)=4.6, p<0.001)$. Post hoc analysis showed that, compared with the maximum number of responses, which usually was observed in bin 2, there was a significant decline in the number of responses in bins 4-12 during all the three extinction sessions $(p<0.05$, Dunnett's $t$-tests). Despite an apparent trend during the third extinction session in which responding was lower during all sequential bins following Org24598 compared with vehicle pretreatment (Figure 1a, Extinction 3), ANOVA revealed no significant main effect of drug treatment or a drug $\times$ bin interaction. Analysis of responding during the first component of each extinction session did not reveal any significant differences between vehicle and Org24598 pretreatments (Supplementary Figure S1A).

Averaged over the entire session, the rate of responding during the three weekly extinction sessions also declined markedly under both the vehicle + extinction and Org24598 + extinction conditions (Figure 1b; Extinction). Although ANOVA revealed no significant main effect of drug, session, or drug-session interaction, there was an overall monotonic decline in average response rate across the three weekly Org24598 + extinction sessions. In contrast, vehicle + extinction conditions produced a monotonic increase in average response rates across the three sessions.

Testing for reacquisition shows that pretreatment with Org24598 during extinction training significantly inhibited subsequent reacquisition of cocaine self-administration compared with pretreatment with vehicle during extinction a - Vehicle - Org24598 (3.0 mg/kg) - Org24598 (7.5 mg/kg)
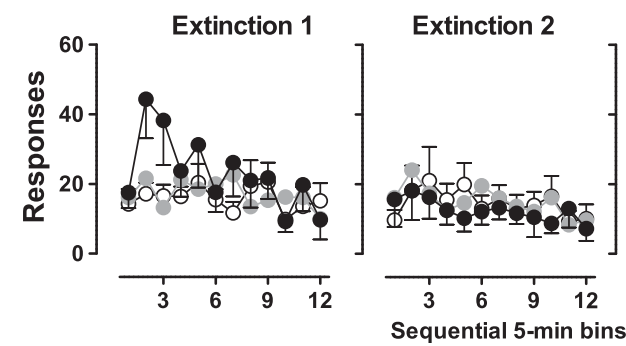

Extinction 3

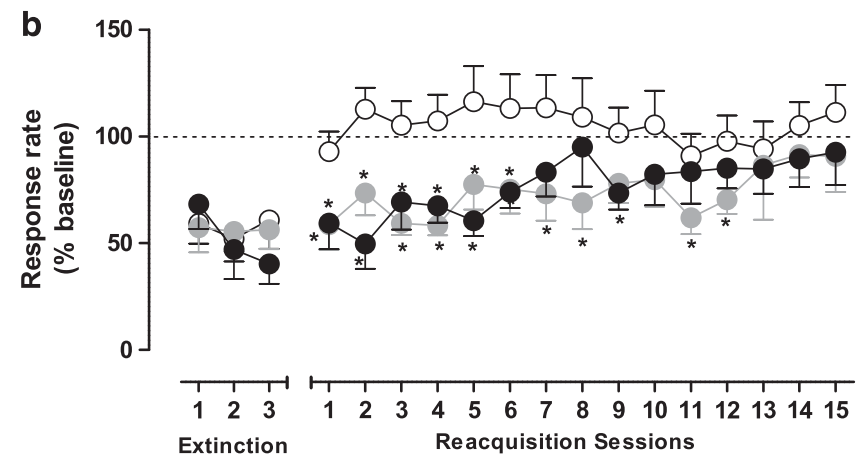

Figure 2 Effects of pre-session administration of Org24598 $(3.0 \mathrm{mg} / \mathrm{kg}$; $n=8$ and $7.5 \mathrm{mg} / \mathrm{kg} ; n=8)$, or vehicle $(n=10)$ in rats. (a) Mean ( \pm SEM) number of responses during sequential 5-min bins of each of the three weekly extinction sessions. (b) Responding during weekly extinction training sessions and daily reacquisition sessions following Org24598+ extinction and vehicle + extinction. Data are presented as mean $( \pm$ SEM) response rates expressed as a percentage of baseline responding.

training (Figure $1 \mathrm{~b}$; reacquisition). ANOVA revealed a significant main effect of drug treatment $(\mathrm{F}(1,62)=8.8$, $p<0.05)$, and post-hoc analysis showed that compared with vehicle, Org24598 treatment before extinction resulted in a significant attenuation of responding during the 2 nd and 4 th-10th reacquisition sessions ( $p<0.05$, Dunnett's $t$-test). Analysis of response rates during the first component of each reacquisition session revealed no significant differences between vehicle + extinction and Org24598 + extinction conditions (Supplementary Figure S1A).

\section{Effects of Pre-session Org24598 on Extinction and Reacquisition in Rats}

As in monkeys, the average rate of responding declined during extinction training under both the vehicle + extinction and Org24598 + extinction conditions compared with the baseline (Figure 2; Supplementary Table S2). Analysis of the within-session patterns of responding during each extinction session revealed a significant main effect of sequential bins for Extinction $1(\mathrm{~F}(11,253)=3.7, p<0.001)$, Extinction $2(\mathrm{~F}(11,253)=2.2, p<0.02)$, and Extinction $3(\mathrm{~F}(11$, $253)=2.0, p<0.03)$. Compared with bins containing the highest number of responses (bin 2 or 3 ), there was a significant decrease in the number of responses in bins 6 and 10-12 (Extinction 1), bins 11-12 (Extinction 2) and bin 12 (Extinction 3) by post-hoc analysis (Figure 2a; $p<0.05$, Dunnett's $t$-test). Analysis of response rates during the first component of extinction sessions did not reveal any significant differences between vehicle + extinction and 
Org24598 + extinction conditions (Supplementary Figure S1B). Averaged over the entire session, the rate of responding declined following both vehicle and Org24598 pretreatment (Figure 2b; Extinction). Pretreatment with Org24598 (3.0 or $7.5 \mathrm{mg} / \mathrm{kg}$ ) during extinction training resulted in a significant inhibition of reacquisition of cocaine selfadministration compared with pretreatment with vehicle (Figure 2b; reacquisition). ANOVA revealed a significant main effect of drug treatment $(\mathrm{F}(2,23)=3.9, p<0.04)$, and post-hoc analysis showed that compared with vehicle, Org24598 treatment before extinction resulted in a significant attenuation of responding during the first seven reacquisition sessions (both doses), as well as the 8th, 11th and 12th sessions $(3.0 \mathrm{mg} / \mathrm{kg}$ Org24598), and 9th session $(7.5 \mathrm{mg} / \mathrm{kg}$ Org24598) $(p<0.05$, Dunnett's $t$-tests). For the rate of responding during the first component of each reacquisition session, ANOVA revealed a main effect of session $(\mathrm{F}(14,322)=3.8, p<0.001)$, but not of treatment (Supplementary Figure S1B).

Effects of Org24598 Treatment Under the Cocaine Self-administration and Abstinence Control Conditions in Monkeys and Rats

When Org24598 was administered before three weekly cocaine self-administration sessions, the average response rates remained at or near cocaine self-administration baseline values, and no significant differences across sessions for monkeys or rats were observed (Supplementary Figure S2). Vehicle treatment in rats before weekly self-administration control sessions produced results similar to those of Org24598 (data not shown). Inspection of response rates during sequential 5-min bins of each session showed stable temporal patterns of responding that did not vary appreciably over the three weekly control sessions (Supplementary Figure S2).

During the reacquisition phases following Org24598+ self-administration or Org24598 + abstinence, the average rate of responding during the 15 sessions did not vary markedly from baseline in either monkeys or rats, as illustrated in Figures 3a and 4a. Vehicle treatment in rats before weekly self-administration or abstinence control sessions produced results similar to those of Org24598 (data not shown). ANOVAs comparing the two control conditions (self-administration and abstinence) to extinction over sequential five-session blocks during the reacquisition phase showed a significant condition $\times$ block interaction in monkeys $(\mathrm{F}(2,91)=4.3, p<0.05)$ and a significant main effect of condition in rats with both $3.0 \mathrm{mg} / \mathrm{kg}$ Org2 24598 $(\mathrm{F}(1,13)=8.5, p<0.02)$ and $7.5 \mathrm{mg} / \mathrm{kg} \operatorname{Org} 24598(\mathrm{~F}(2$, $18)=5.5, p<0.01)$. Post hoc analysis further revealed that the response rates were significantly higher following Org24598 + self-administration control and Org24598 + abstinence control compared with Org24598 + extinction training in both monkeys and rats for most five-session blocks (Figures $3 \mathrm{~b}$ and $4 \mathrm{~b} ; p<0.01$ or $p<0.05$, Dunnett's $t$-test). The exceptions were the comparable response rates following Org24598 + extinction and Org24598 + self-administration during the last five-session block in monkeys (Figure $3 \mathrm{~b}$ ) and $7.5 \mathrm{mg} / \mathrm{kg}$ Org24598 + extinction and $7.5 \mathrm{mg} / \mathrm{kg}$ Org24598 + abstinence during the last five-session block in rats (Figure $4 \mathrm{~b}$ ).
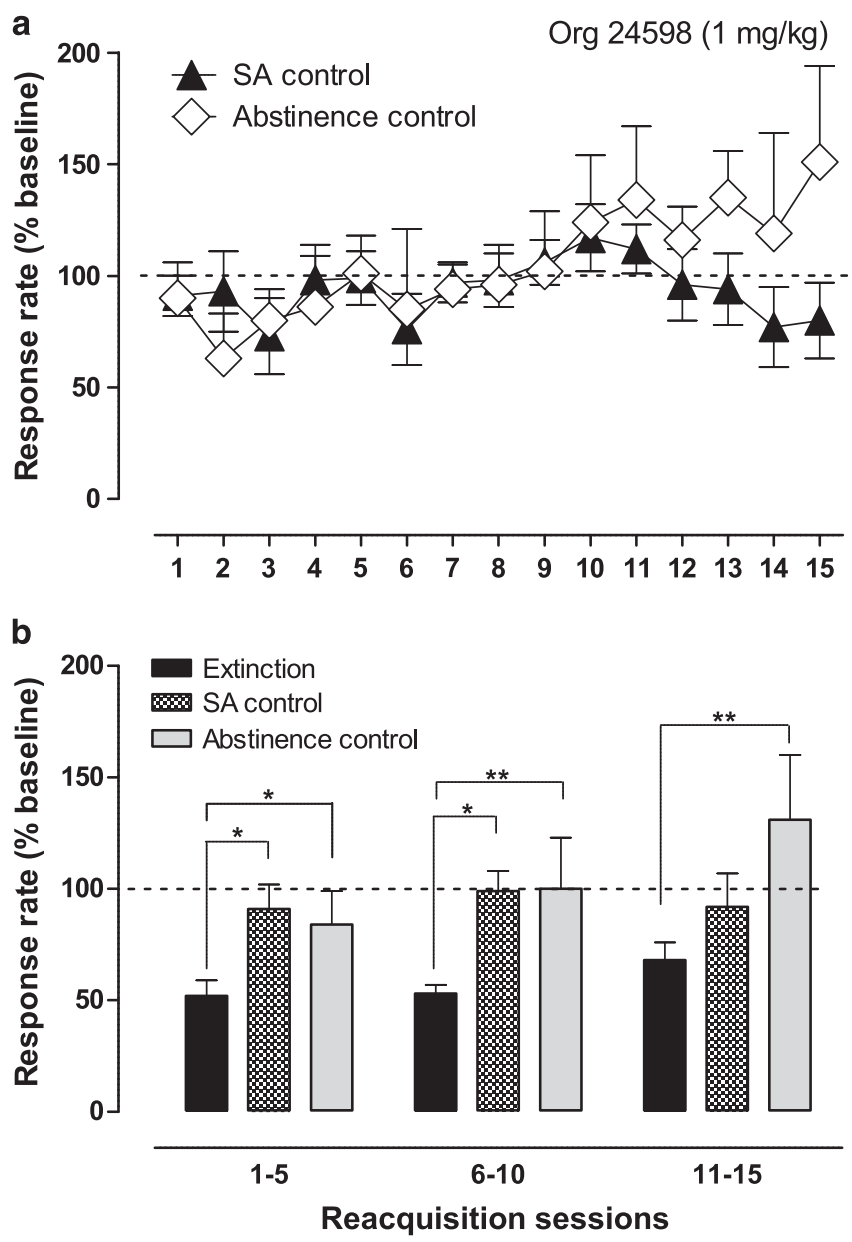

Figure 3 Reacquisition of cocaine self-administration following Org24598 in the absence of extinction training in monkeys. Data are mean $( \pm$ SEM) response rates expressed as a percentage of baseline responding. (a) Daily response rates during reacquisition test sessions following Org24598 + self-administration control $(n=5)$ and Org24598 + abstinence control $(n=6)$. (b) Response rates across five-session blocks of reacquisition following Org24598 combined with extinction, self-administration control, or abstinence control. $* p<0.05$, ** $p<0.0$ I compared with Org24598 + extinction.

\section{Effects of Post-session Administration of Org24598 in Monkeys}

When Org24598 $(1 \mathrm{mg} / \mathrm{kg})$ or vehicle was administered to monkeys following, rather than preceding, each of three weekly extinction sessions, the average rate of responding declined rapidly to a level that was comparable to the rate observed when Org24598 or vehicle was administered as a pretreatment (Figure 5a, Extinction). Analysis of responding across the three weekly extinction sessions by ANOVA revealed no significant effect of treatment $(F(1,6)=0.6$, $p>0.05)$ or extinction session $(\mathrm{F}(2,6)=0.03 ; p>0.05)$. However, unlike the effects seen with pre-session Org24598 treatment, reacquisition of cocaine self-administration occurred within just a few sessions under both the Org24598 and vehicle post-session treatment conditions (Figure 5a, reacquisition). ANOVA revealed no significant effects of treatment $(\mathrm{F}(1,36)=0.9, p>0.05)$ or reacquisition session $(\mathrm{F}(14,36)=0.4, p>0.05)$. 

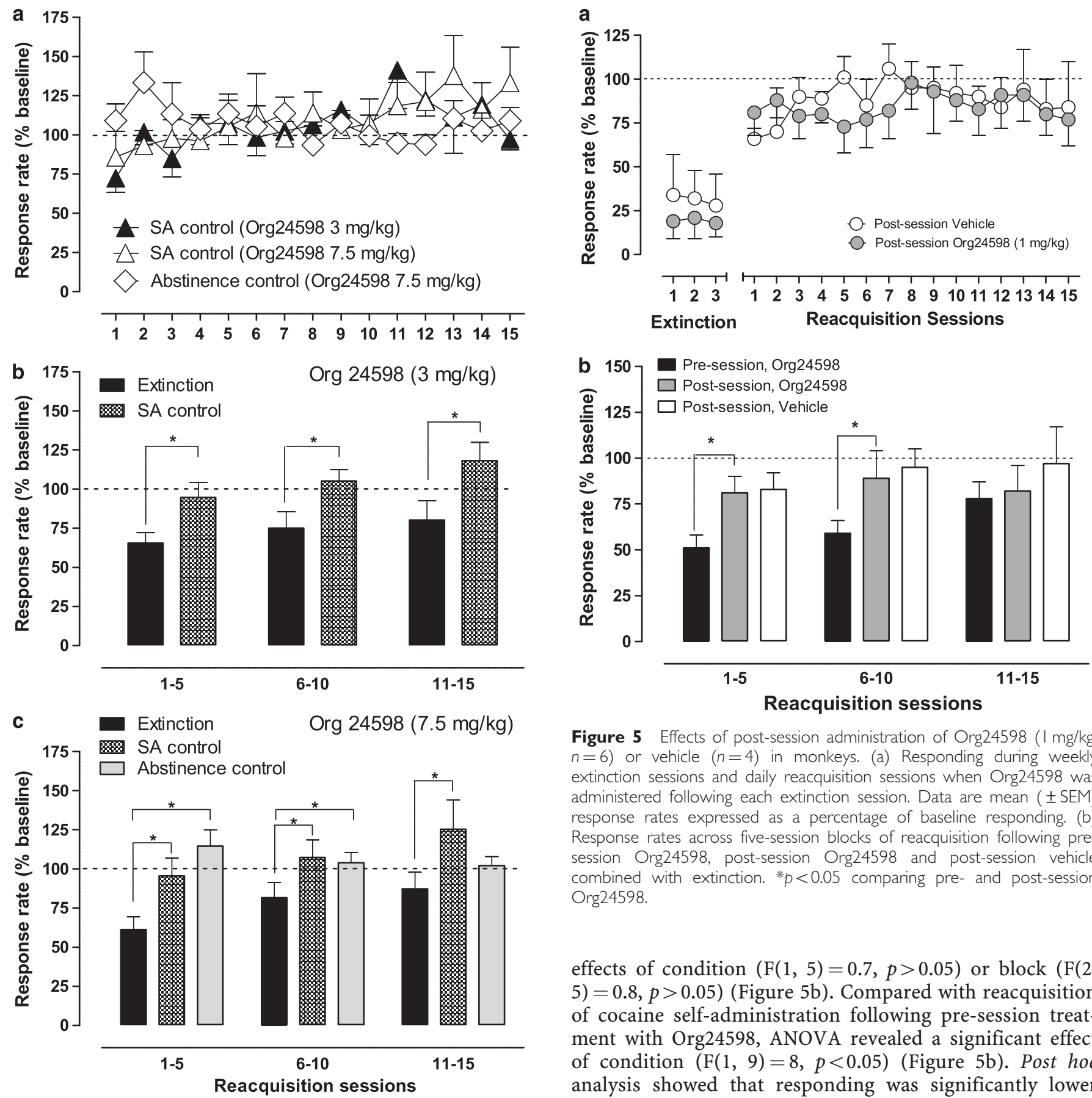

Figure 5 Effects of post-session administration of Org24598 (I mg/ $/ \mathrm{kg}$; $n=6)$ or vehicle $(n=4)$ in monkeys. (a) Responding during weekly extinction sessions and daily reacquisition sessions when Org24598 was administered following each extinction session. Data are mean $( \pm$ SEM) response rates expressed as a percentage of baseline responding. (b) Response rates across five-session blocks of reacquisition following presession Org24598, post-session Org24598 and post-session vehicle combined with extinction. ${ }^{*} p<0.05$ comparing pre- and post-session Org24598.

effects of condition $(\mathrm{F}(1,5)=0.7, p>0.05)$ or block $(\mathrm{F}(2$, $5)=0.8, p>0.05)$ (Figure $5 \mathrm{~b}$ ). Compared with reacquisition of cocaine self-administration following pre-session treatment with Org24598, ANOVA revealed a significant effect of condition $(\mathrm{F}(1,9)=8, p<0.05)$ (Figure $5 \mathrm{~b})$. Post hoc analysis showed that responding was significantly lower across the first 10 days of reacquisition following pre-session treatment with Org24598 compared with post-session treatment with Org24598 ( $p<0.05$, Dunnett's $t$-test). in the absence of extinction in rats. Data are mean ( \pm SEM) response rates expressed as a percentage of baseline responding. (a) Daily response rates during reacquisition test sessions following Org24598 + selfadministration control ( $n=7$ per dose) and Org24598+abstinence control $(n=6)$. (b) Response rates over five-session blocks of reacquisition following $3.0 \mathrm{mg} / \mathrm{kg}$ Org24598 + extinction compared with $3.0 \mathrm{mg} / \mathrm{kg}$ Org24598 + self-administration control. (c) Response rates over fivesession blocks of reacquisition following $7.5 \mathrm{mg} / \mathrm{kg}$ Org $24598+$ extinction compared with $7.5 \mathrm{mg} / \mathrm{kg}$ Org 24598 + self-administration or $7.5 \mathrm{mg} / \mathrm{kg}$ Org24598 + abstinence controls. $* p<0.05$ compared with Org24598+ extinction.

Comparison of responding over sequential five-session blocks of the reacquisition phase following post-session Org24598 or post-session vehicle also revealed no significant

\section{DISCUSSION}

The present results show that the GlyT1 inhibitor, Org24598, when administered before weekly extinction training sessions, inhibited the reacquisition of cocaine self-administration compared with extinction training conducted in the absence of Org24598. Administration of Org24598 in the absence of extinction training (ie, before self-administration and abstinence control sessions) did not inhibit reacquisition of cocaine self-administration in either monkeys or rats. 
The latter results indicate that extinction training is a necessary component for inhibiting reacquisition of cocaine self-administration after Org24598 pretreatment. These findings are supported by recent reports using cognitiveenhancing drugs in cocaine-trained rats and monkeys (Nic Dhonnchadha et al, 2010, 2011) and extend the previous work by demonstrating enduring effects on reacquisition of cocaine self-administration by pharmacological inhibition of GlyT1 during cocaine-cue extinction training.

In vitro, Org24598 inhibits glycine uptake in cells expressing the GlyT1 transporter at nanomolar concentrations (Mallorga et al, 2003). In vivo, Org24598 increases glycine release in the nucleus accumbens by $\sim 50 \%$, (Lidö et al, 2011) at doses comparable with the higher dose tested $(7.5 \mathrm{mg} / \mathrm{kg})$ in our study in rats. As at least a $40 \%$ increase in glycine levels is sufficient to potentiate NMDA receptor activity (Atkinson et al, 2001) and because compounds acting as glycine transporter 1 inhibitors have been shown to increase excitatory synaptic transmission via NMDA receptors (Atkinson et al, 2001; Chen et al, 2003), it is likely that Org24598 inhibited the reacquisition of cocaine self-administration by facilitating some aspects of the extinction process shown to require NMDA receptor-mediated synaptic transmission (BurgosRobles et al, 2007; Sotres-Bayon et al, 2007). This is particularly relevant to this study, as long-term exposure to cocaine in rodents can disrupt NMDA receptor function and expression in neural networks involved in extinction learning, eg, the hippocampus, frontal cortex and striatum (Loftis and Janowsky, 2002; Self et al, 2004; Turchan et al, 2003; Yamaguchi et al, 2002). Alternative receptor mechanisms by which Org24598 can influence extinction learning could involve increased activation of glycine receptors and elevation of dopamine levels in the nucleus accumbens (Lidö et al, 2011). The latter effect, however, would likely result in an increase, rather than decrease in the reacquisition to cocaine self-administration in this study, which was not observed.

Following Org24598 + extinction training, responding during reacquisition test sessions diminished to $\sim 50 \%$ of the rate of responding during baseline cocaine selfadministration and this effect persisted for as many as twelve reacquisition sessions. Qualitatively, similar effects on reacquisition has been found in studies using similar experimental designs to evaluate the effects of combining extinction training with other glycinergic agents, including the NMDA receptor partial agonist D-cycloserine (DCS) and the GlyT1 inhibitor, RO4543338 (Nic Dhonnchadha et al, $2010,2011)$. This inhibitory effect of Org24598 on relapse to cocaine seeking could potentially reflect facilitated acquisition, consolidation, or retrieval (recall) of extinction learning (Quirk and Mueller, 2008) as the NMDA receptor is an important molecule for all three processes (BurgosRobles et al, 2007; Sotres-Bayon et al, 2007). Acquisition of extinction is the initial learning manifested by reduced responding within an extinction session (Quirk and Mueller, 2008). In the present study, Org24598 and vehicle pretreatments reduced responding in each extinction session to similar degrees, suggesting that the acquisition phase of extinction was not facilitated by Org24598. In our previous study, pretreatment with an NMDA receptor partial agonist, DCS, also inhibited reacquisition without affecting responding during extinction learning in monkeys
(Nic Dhonnchadha et al, 2010). It is therefore possible that cognitive-enhancing drugs administered during extinction training can inhibit subsequent reacquisition of cocaine self-administration without facilitating the acquisition of extinction learning.

Consolidation of extinction memory that occurs within a few hours after an extinction session to stabilize memories (Inda et al, 2005) has been proposed as an important phase at which cognitive-enhancing drugs can act to reduce drug relapse (eg, Nic Dhonnchadha et al, 2010; Torregrossa et al, 2010). In the present study, post-session Org24598 treatments resulted in reacquisition to cocaine seeking that was not attenuated compared with either post-session vehicle or pre-session Org24598 treatments. This suggests that enhanced consolidation of extinction memory by Org24598 does not appear to be the primary mechanism underlying the inhibition of reacquisition. However, this conclusion should be interpreted cautiously, because post-session Org24598 effects were studied after pre-session Org24598 studies were completed in monkeys. Furthermore, postsession DCS inhibited the reacquisition of cocaine selfadministration in rats only under conditions of increased arousal (Nic Dhonnchadha et al, 2010), and there was no explicit attempt to elicit post-session arousal in monkeys in this study.

Considered from another perspective, Org24598 treatment before the three weekly extinction sessions may have influenced processes underlying extinction retrieval, resulting in better recall of extinction memory during the reacquisition phase and thereby reducing relapse to cocaine seeking. This possibility is based on findings that presentation of an extinguished conditioned stimulus can trigger retrieval of extinction memory, resulting in low levels of conditioned responding (Quirk and Mueller, 2008). Poor retrieval of extinction memory, on the other hand, is characterized by high levels of conditioned responding. In animals that received vehicle during the extinction phase, cocaine self-administration was reacquired within just a few sessions, suggesting comparatively poor retrieval of the extinction memory. In contrast, animals that received Org24598 during the extinction phase showed a prolonged attenuation of cocaine seeking during reacquisition, suggesting that extinction memory was more efficiently retrieved than in the case of vehicle-treated animals. The pattern of reduced cocaine seeking following extinction training combined with Org24598 suggests that animals had increased resistance to reestablishing the association between cocaine and the cue, even after multiple intravenous cocaine injections were delivered.

Although the precise neurobiological mechanisms by which glycinergic compounds can influence extinction learning are unclear, the study provides preclinical evidence of the utility of compounds acting via GlyT1 inhibition to promote extinction learning and subsequently reduce cocaine self-administration. Inhibition of relapse for a prolonged period of time following extinction, as observed in this study, might provide a significant window of opportunity during which additional therapeutic interventions could be introduced to further forestall relapse. For example, stress is a major determinant of relapse (Sinha, 2009) and cognitive behavioral therapies that help to develop coping skills have been effective in treating alcohol 
abuse (O'Malley et al, 2007). As evidenced by the eventual return to baseline levels of responding toward the end of the reacquisition phase of our study, pharmacologically augmented exposure therapy might be most beneficial if implemented as a recurring treatment strategy for the management of cocaine dependence. To advance these findings to clinical practice, further translational research is necessary to investigate candidate pharmacotherapies and understand the mechanisms by which glycinergic compounds can augment the different phases of extinction learning, including acquisition, consolidation, and retrieval processes.

\section{ACKNOWLEDGEMENTS}

This research was financially supported by the National Institute on Drug Abuse through grants DA024315 and DA024315-S1 and by the National Center for Research Resources (RR00168) and is currently supported by the Office of Research Infrastructure Programs/OD OD011103. We are grateful for the excellent technical assistance of Laura Teixeira, Eileen Curran and Rebecca Smith of the New England Primate Research Center of Harvard Medical School and Leif Hede-Brierley, Jamar Whaley and Samantha Shelton of Boston University.

\section{DISCLOSURE}

Over the past three years, DMP has received funding from Addiction Therapeutix on projects unrelated to this study. The remaining authors declare no conflict of interest.

\section{REFERENCES}

Achat-Mendes C, Grundt P, Cao J, Platt DM, Newman AH, Spealman RD (2010). Dopamine D3 and D2 receptor mechanisms in the abuse-related behavioral effects of cocaine: studies with preferential antagonists in squirrel monkeys. J Pharmacol Exp Ther 334: 556-565.

Atkinson BN, Bell SC, De Vivo M, Kowalski LR, Lechner SM, Ognyanov VI et al (2001). ALX 5407: a potent, selective inhibitor of the hGlyT1 glycine transporter. Mol Pharmacol 60: 1414-1420.

Brown A, Carlyle I, Clark J, Hamilton W, Gibson S, McGarry G et al (2001). Discovery and SAR of Org24598-a selective glycine uptake inhibitor. Bioorg Med Chem Lett 11: 2007-2009.

Burgos-Robles A, Vidal-Gonzalez I, Santini E, Quirk GJ (2007). Consolidation of fear extinction requires NMDA receptordependent bursting in the ventromedial prefrontal cortex. Neuron 53: 871-880.

Chen L, Mulhauser M, Yang CR (2003). Glycine transporter-1 blockade potentiates NMDA mediated responses in rat prefrontal cortical neurons in vitro and in vivo. J Neurophysiol 89: 691.

Childress AR, Mozley PD, McElgin W, Fitzgerald J, Reivich M, O’Brien CP (1999). Limbic activation during cue-induced cocaine craving. Am J Psychiatry 156: 11-18.

Cleva RM, Gass JT, Widholm JJ, Olive MF (2010). Glutamatergic targets for enhancing extinction learning in drug addiction. Curr Neuropharmacol 8: 394-408.

Dubroqua S, Singer P, Boison D, Feldon J, Möhler H, Yee BK (2010). Impacts of forebrain neuronal glycine transporter 1 disruption in the senescent brain: evidence for age-dependent phenotypes in Pavlovian learning. Behav Neurosci 124: 839-850.

Feltenstein MW, See RE (2007). NMDA receptor blockade in the basolateral amygdala disrupts consolidation of stimulus-reward memory and extinction learning during reinstatement of cocaine-seeking in an animal model of relapse. Neurobiol Learn Mem 88: 435-444.

Goldstein RZ, Tomasi D, Alia-Klein N, Honorio Carrillo J, Maloney T, Woicik PA et al (2009). Dopaminergic response to drug words in cocaine addiction. J Neurosci 29: 6001-6006.

Hofmann SG (2007). Enhancing exposure-based therapy from a translational research perspective. Behav Res Ther 45: 1987-2001.

Inda MC, Delgado-García JM, Carrión AM (2005). Acquisition, consolidation, reconsolidation, and extinction of eyelid conditioning responses require de novo protein synthesis. J Neurosci 25: $2070-2080$.

Kilts CD, Schweitzer JB, Quinn CK, Gross RE, Faber TL, Muhammad $\mathrm{F}$ et al (2001). Neural activity related to drug craving in cocaine addiction. Arch Gen Psychiatry 58: 334-341.

Kinney GG, Sur C, Burno M, Mallorga PJ, Williams JB, Figueroa DJ et al (2003). The glycine transporter type 1 inhibitor $\mathrm{N}-\left[3-\left(4^{\prime}-\right.\right.$ fluorophenyl)-3-(4'-phenylphenoxy)propyl] sarcosine potentiates NMDA receptor-mediated responses in vivo and produces an antipsychotic profile in rodent behavior. J Neurosci 23: 7586-7591.

Le Pen G, Kew J, Alberati D, Borroni E, Heitz MP, Moreau JL (2003). Prepulse inhibition deficits of the startle reflex in neonatal ventral hippocampal-lesioned rats: reversal by glycine and a glycine transporter inhibitor. Biol Psychiatry 54: 1162-1170.

Lidö HH, Marston H, Ericson M, Söderpalm B (2011). The glycine reuptake inhibitor Org24598 and acamprosate reduce ethanol intake in the rat; tolerance development to acamprosate but not to Org24598. Addict Biol (e-pub ahead of print 28 September 2011) doi:10.1111/j.1369-1600.2011.00367.

Liem-Moolenaar M, Zoethout RW, de Boer P, Schmidt M, de Kam ML, Cohen AF et al (2010). The effects of the glycine reuptake inhibitor R213129 on the central nervous system and on scopolamine-induced impairments in psychomotor and cognitive function in healthy subjects. J Psychopharmacol 24: 1671-1679.

Loftis JM, Janowsky A (2002). Cocaine treatment- and withdrawalinduced alterations in the expression and serine phosphorylation of the NR1 NMDA receptor subunit. Psychopharmacology (Berl) 64: 349-359.

Mallorga PJ, Williams JB, Jacobson M, Marques R, Chaudhary A, Conn PJ et al (2003). Pharmacology and expression analysis of glycine transporter GlyT1 with [3H]-(N-[3-(4'-fluorophenyl)-3(4'phenylphenoxy)propyl])sarcosine. Neuropharmacology 45: 585-593.

Myers KM, Carlezon WA Jr, Davis M (2011). Glutamate receptors in extinction and extinction-based therapies for psychiatric illness. Neuropsychopharmacology 36: 274-293.

Nic Dhonnchadha BÁ, Pinard E, Alberati D, Wettstein JG, Spealman RD, Kantak KM (2011). Inhibiting glycine transporter-1 facilitates cocaine-cue extinction and attenuates reacquisition of cocaine-seeking behavior. Drug Alcohol Depend 122: 119-126.

Nic Dhonnchadha BÁ, Szalay JJ, Achat-Mendes C, Platt DM, Otto MW, Spealman RD et al (2010). D-cycloserine deters reacquisition of cocaine self-administration by augmenting extinction learning. Neuropsychopharmacology 35: 357-367.

Nikiforuk A, Kos T, Rafa D, Behl B, Bespalov A, Popik P (2011). Blockade of glycine transporter 1 by SSR-504734 promotes cognitive flexibility in glycine/NMDA receptor-dependent manner. Neuropharmacology 61: 262-267.

O’Malley SS, Sinha R, Grilo CM, Capone C, Farren CK, McKee SA et al (2007). Naltrexone and cognitive behavioral coping skills therapy for the treatment of alcohol drinking and eating disorder features in alcohol-dependent women: a randomized controlled trial. Alcohol Clin Exp Res 31: 625-634.

Platt DM, Carey G, Spealman RD (2011). Models of neurological disease (substance abuse): self-administration in monkeys. Curr Protoc Pharmacol; Chapter 10:Unit 10.5.

Quirk GJ, Mueller D (2008). Neural mechanisms of extinction learning and retrieval. Neuropsychopharmacology 33: 56-72. 
Robinson T, Berridge KC (2001). Incentive-sensitization and addiction. Addiction 96: 106-114.

Self DW, Choi KH, Simmons D, Walker JR, Smagula CS (2004). Extinction training regulates neuroadaptive responses to withdrawal from chronic cocaine self-administration. Learn Mem 11: 648-657.

Singer P, Feldon J, Yee BK (2009). The glycine transporter 1 inhibitor SSR504734 enhances working memory performance in a continuous delayed alternation task in C57BL/6 mice. Psychopharmacology (Berl) 202: 371-384.

Sinha R (2009). Modeling stress and drug craving in the laboratory: implications for addiction treatment development. Addict Biol 14: 84-98.

Sotres-Bayon F, Bush DE, LeDoux JE (2007). Acquisition of fear extinction requires activation of NR2B-containing NMDA receptors in the lateral amygdala. Neuropsychopharmacology 32: $1929-1940$.

Torregrossa MM, Sanchez H, Taylor JR (2010). D-cycloserine reduces the context specificity of pavlovian extinction of cocaine cues through actions in the nucleus accumbens. J Neurosci 30: 10526-10533.
Turchan J, Maj M, Przewlocka B (2003). The effect of drugs of abuse on NMDAR1 receptor expression in the rat limbic system. Drug Alcohol Depend 72: 193-196.

Volkow ND, Wang GJ, Telang F, Fowler JS, Logan J, Childress AR et al (2006). Cocaine cues and dopamine in dorsal striatum: mechanism of craving in cocaine addiction. J Neurosci 26: 6583-6588.

Wallace TL, Ballard TM, Pouzet B, Riedel WJ, Wettstein JG (2011). Drug targets for cognitive enhancement in neuropsychiatric disorders. Pharmacol Biochem Behav 99: 130-145.

Wong DF, Kuwabara H, Schretlen DJ, Bonson KR, Zhou Y, Nandi A et al (2006). Increased occupancy of dopamine receptors in human striatum during cue-elicited cocaine craving. Neuropsychopharmacology 31: 2716-2727.

Yamaguchi M, Suzuki T, Abe S, Hori T, Kurita H, Asada T et al (2002). Repeated cocaine administration differentially affects NMDA receptor subunit (NR1, NR2A-C) mRNAs in rat brain. Synapse 46: 157-169.

Zweifel LS, Argilli E, Bonci A, Palmiter RD (2008). Role of NMDA receptors in dopamine neurons for plasticity and addictive behaviors. Neuron 59: 486-496.

Supplementary Information accompanies the paper on the Neuropsychopharmacology website (http://www.nature.com/npp) 